\title{
Commentary \\ A new day dawns: women without oestrogen or is a balance best?
}

\author{
V Craig Jordan
}

Robert H Lurie Comprehensive Cancer Center, The Feinberg School of Medicine, Northwestern University, Chicago, IL, USA

Correspondence: Professor V Craig Jordan, Robert H Lurie Comprehensive Cancer Center, The Feinberg School of Medicine, Northwestern University, Chicago, IL, USA. Tel: +1 312908 4148; fax: +1 312908 1372; e-mail: vcjordan@northwestern.edu

Received: 10 July 2002

Breast Cancer Res 2002, 4:218-221 (DOI 10.1186/bcr538)

Revisions requested: 18 July 2002

Revisions received: 18 July 2002

Accepted: 20 August 2002

Published: 10 September 2002

(C) 2002 BioMed Central Ltd

(Print ISSN 1465-5411; Online ISSN 1465-542X)

This article was written in reply to a commentary from Michael Baum, http://breast-cancer-research/content/4/6/213

\begin{abstract}
Building on the 30-year success story with tamoxifen, the question now is whether one agent can be used for treatment and prevention or should new medicines be targeted to specific applications? The early results with anastrozole suggest it could replace tamoxifen for treatment and should be tested as a preventive. Unfortunately, long-term testing of aromatase inhibitors will be required to avoid concerns about osteoporosis, Alzheimer's disease and coronary heart disease. Most importantly, the knowledge gained with tamoxifen has resulted in a new generation of selective oestrogen receptor modulators that can be used to prevent osteoporosis, breast cancer and uterine cancer. It is now clear that strategies utilising aromatase inhibitors and selective oestrogen receptor modulators will provide much needed options for individualised treatments.
\end{abstract}

Keywords: anastrozole, aromatase inhibitor, raloxifene, selective oestrogen receptor modulator, tamoxifen

\section{Introduction}

"The only true antiestrogen is no estrogen" was the statement made by Terry Robinson during a discussion of a presentation entitled 'Antiestrogens' by Professor Cliff Emmens at the Laurentian Hormone Conference in 1961 [1]. During the past 40 years, however, a profound change has occurred in the practice of cancer therapeutics, and medical oncology has entered the era of molecular medicine.

Tamoxifen, a nonsteroidal anti-oestrogen, is established as one of the first successful targeted therapies that has prevented the deaths of 400,000 patients (Dr George Blackledge, AstraZeneca UK, personal communication, 2002) with oestrogen receptor (OER)-positive tumours [2]. Remarkably, sufficient experience was accrued with tamoxifen during the 1970 s and 1980 s to be able to ask whether the medicine had worth in reducing the incidence of breast cancer in high-risk premenopausal and postmenopausal women. In 1998, Professor Bernard Fisher, perhaps the most accomplished clinical trialist in the world, reported the results from the first prospective, placebo-controlled, breast cancer prevention trial (National Surgical Adjuvant Breast and Bowel Project [P-1]) [3] and the answer was "yes". As a consequence of the landmark accomplishment by the P-1 trial, tamoxifen is now available in the United States for the reduction (50\%) of breast cancer incidence in premenopausal and postmenopausal women at elevated risk [4].

I propose that the advance in progress with the early results of the Anastrozole, Tamoxifen Alone or in Combination (ATAC) trial should be placed in context and exam- 
ined outside the single dimension of a 'new and improved' drug to be substituted for tamoxifen everywhere in medical practice. In other words, the needs of the breast cancer patients to stay alive, with fewer troublesome side effects, are very different from the healthy woman at high risk for breast cancer who needs to reduce her risk.

At the dawn of this new day what are the facts, how should they be interpreted, and are there reasonable alternatives for chemoprevention that need to be considered?

\section{The ATAC trial}

The facts, simply stated, are as follows. The early results (about 3 years) of an international adjuvant treatment study, of 5 years of tamoxifen versus anastrozole versus the combination of tamoxifen and anastrozole, show a disease-free advantage for 'no oestrogen' (anastrozole) versus an 'anti-oestrogen' (tamoxifen). The advantage is shown by reducing recurrences in a huge population of OER (or unknown) node-positive (30\%) and nodenegative (70\%) breast cancer patients [5]. Additionally, 'no oestrogen' is better than the 'anti-oestrogen' at reducing the incidence of contralateral (primary) breast cancer.

These encouraging antitumour results, coupled with a reduced incidence of endometrial cancers and thromboembolic disorders, suggest that aromatase inhibition increases efficacy and reduces side effects. This dual bonus is in fact historically much better than when tamoxifen was first introduced. At that time, tamoxifen was found to have fewer side effects but the same efficacy when compared with the standard of care (diethylstilboestrol) for the treatment of advanced breast cancer [6]. That is why tamoxifen went forward with evaluation as an adjuvant therapy. Clearly, if the early results of the ATAC trial prove to be consistent over the next few years, a new day will dawn for treatment. But it would be preferable, in the new age of targeted therapies, to establish mechanisms for these increased benefits first, so as not to be condemned to relive the past.

\section{Muddled mechanisms}

The presence of the OER is critical for the mechanisms of actions for both tamoxifen (blocking anti-oestrogen) and of anastrozole (oestrogen biosynthesis inhibitor). Ideas that mechanisms other than the OER could be responsible for tamoxifen's actions [7] have not stood the test of time [2]. This is why it has been so important to embrace this basic concept of molecular medicine and to establish uniform OER assays in the United Kingdom [8].

The OER remains the most effective target for breast cancer therapeutics, and it is now imperative that we advance further to determine why some patients respond to anastrozole rather than to tamoxifen. The most probable explanation is that the OER-positive tumour with ErbB1/2 positivity subverts the inhibitory action of tamoxifen. These OER-positive, ErbB1/2-positive patients could be identified to establish whether anastrozole and tamoxifen are equivalent in the patients with OER-positive, ErbB1/2negative tumours. This would support the preliminary observation that tamoxifen is less effective than an aromatase inhibitor in ErbB1/2-positive and OER-positive patients [9]. Interestingly enough, those patients in the ATAC trial who were at greatest risk of recurrence also received chemotherapy, but there was no difference between tamoxifen and anastrozole treatment in this substantial subgroup [5]. This also suggests that ErbB2 has a role.

\section{Hazards of early reporting}

The goal of the ATAC trial is to refine the established breakthrough made by tamoxifen. Unfortunately, it is not easy to be absolutely sure that early data will remain consistent because only one-half of the required 5 years of treatment has so far been given. Indeed, in an editorial in the Lancet, Dr Radvin wondered how many participants will elect to change to anastrozole alone, the safer, more effective agent [10]. Although the primary goal of the ATAC trial was to achieve a disease-free survival advantage for anastrozole, it is hoped that a survival advantage can be established.

If this situation sounds familiar, then that is because it is. Substitute 'P-1 prevention trial' for 'ATAC trial' in the proceeding paragraph and you will recall the parallel. In 1998, the $\mathrm{P}-1$ prevention trial that was conducted in the United States and Canada was reported at the American Society for Clinical Oncology. Prearranged stop rules had been invoked by the independent Endpoint and Safety Monitoring Committee to release the results. In other words, there was a prewritten undertaking to stop the trial if there was a good or bad result of significance. Unlike the ATAC trial, the followup in the P-1 trial was quite impressive: $37 \%$ of 13,688 volunteers had a median followup of longer than 5 years, and $67 \%$ of participants had a followup of longer than 4 years. AstraZeneca played an appropriate role by making tamoxifen available to all volunteers in the placebo arm who wished to start tamoxifen as a chemopreventive. The Food and Drug Administration approved tamoxifen in 1998. The question to be addressed now is whether a single linear view of progress from a pioneering anti-oestrogen to a drug that removes all oestrogen from a woman's body is the only dimension to be considered in chemoprevention.

\section{SERMs: a balance}

John Lennon once wrote "Life is what happens to you when you are making plans to do something else". Progress in medicine is more complex than the single dimension of finding a replacement for tamoxifen because other events of significance occur that should be evalu- 
ated independently. Selective oestrogen receptor modulation (SERM), a concept first recognised in the laboratory in the mid-1980s [11,12], advanced the first agent, raloxifene, to prevent osteoporosis with breast cancer and endometrial safety. The new concept of SERM has created an additional dimension in public health and chemoprevention.

The Multiple Outcomes of Raloxifene Evaluation trial showed an early (3 years) significant decrease in fractures in osteoporotic postmenopausal women, but also showed a beneficial reduction in both breast and endometrial cancer. This was in 1998, and the dramatic findings for a SERM, soon to be on the market, were presented at the American Society for Clinical Oncology at the same meeting as the P-1 trial, and were subsequently published [13]. The STAR (Study of Tamoxifen and Raloxifene) trial in the US is comparing the standard of care tamoxifen with raloxifene in 22,000 postmenopausal women at high risk for breast cancer. Having already evaluated tamoxifen and raloxifene in randomised, placebo-controlled clinical studies with in excess of 20,000 healthy women (P-1 trial plus Multiple Outcomes of Raloxifene Evaluation trial), it was not necessary to include a placebo arm because this is guaranteed to have a higher incidence of breast cancer. Clearly, women do not wish to exercise a wait-and-see policy if risk reduction is proven possible. A high-risk woman in America need only ask her doctor to prescribe one or the other drug (tamoxifen or raloxifene) depending on her preferences.

\section{Chemoprevention and aromatase inhibitors}

Tamoxifen still has a role in the chemoprevention of breast cancer until proven otherwise by clinical trial. Specifically, one-third of breast cancer occurs in premenopausal women, and tamoxifen has an extraordinarily good risk-benefit ratio in premenopausal women [3]. Anastrozole cannot be considered because it is effective only in postmenopausal women. Tamoxifen has no adverse effects on thromboembolic events or endometrial cancer, and projected estimates of overall long-term benefits from tamoxifen as a chemopreventive are highest for premenopausal women [14]. It has already been stressed [15], with tamoxifen coming off patent early next year in the United States, that it will be the only option to provide an extremely cost effective intervention for premenopausal women at risk for breast cancer.

The issue to be considered for the future of chemoprevention in postmenopausal women, therefore, is whether no oestrogen will be superior to a balanced intervention with a new generation of multifunctional medicines or SERMs [16]. I was initially concerned (in the 1980s) that we might prevent breast cancer with tamoxifen but increase the incidence of the two major killers of women, osteoporosis and advanced tamoxifen to become a preventive, but it more importantly advanced the public health strategy of developing drugs to prevent osteoporosis and coronary heart disease in postmenopausal women at risk and to prevent breast cancer as a beneficial side effect [17].

I have never been anti oestrogen, but a clinical trial with an aromatase inhibitor such as the International Breast Intervention Study (IBIS) II trial should only consider the recruitment of women at the highest risk. The possibility of increasing the incidence of Alzheimer's disease, osteoporosis and coronary heart disease in the general population of healthy women seems too high a price to pay when a balance with a new SERM may be best for public health. This vision of progress in chemoprevention depends on the outcome of the Study of Tamoxifen and Raloxifene trial and the Raloxifene Use for the Heart trial [18], and most importantly on the introduction of new SERMs [19] to replace the aging agents tamoxifen and raloxifene.

\section{References}

1. Emmens CW, Cox RI, Martin L: Antiestrogens. Recent Prog Horm Res 1962, 18:415-466.

2. Early Breast Cancer Trialists' Collaborative Group: Tamoxifen for early breast cancer: an overview of the randomised trials. [see comments]. Lancet 1998, 351:1451-1467.

3. Fisher B, Costantino JP, Wickerham DL, Redmond CK, Kavanah M, Cronin WM, Vogel V, Robidoux A, Dimitrov N, Atkins J, Daly M, Wieand S, Tan-Chiu E, Ford L, Wolmark N: Tamoxifen for prevention of breast cancer: report of the National Surgical Adjuvant Breast and Bowel Project P-1 Study. J Natl Cancer Inst 1998, 90:1371-1388.

4. United States Preventive Services Task Force: Chemoprevention of breast cancer: recommendations and rationale. Ann Intern Med 2002, 137:56-58.

5. The ATAC (Arimidex, Tamoxifen Alone or in Combination) Trialists' Group: Anastrozole alone or in combination with tamoxifen versus tamoxifen alone for adjuvant treatment of postmenopausal women with early breast cancer: first results of the ATAC randomized trial. Lancet 2002, 359:2131-2139.

6. Ingle JN, Ahmann DL, Green SJ, Edmonson JH, Bisel HF, Kvols LK, Nichols WC, Creagan ET, Hahn RG, Rubin J, Frytak S: Randomized clinical trial of diethylstilbestrol versus tamoxifen in postmenopausal women with advanced breast cancer. $N$ Engl J Med 1981, 304:16-21.

7. Colletta AA, Benson JR, Baum M: Alternative mechanisms of action of antioestrogens. Breast Cancer Res Treat 1994, 31:59.

8. Wishart GC, Gaston M, Poultsidis AA, Purushotham AD: Hormone receptor status in primary breast cancer - time for a consensus? Eur J Cancer 2002, 38:1201-1203.

9. Ellis MJ, Coop A, Singh B, Mauriac L, Llambert F, Cussac A, Janicke F, Miller WR, Evans DB, Dugan M, Brady C, QuebeFehling $E$, Borgs $M$ : Letrozole is more effective neoadjuvant endocrine therapy then tamoxifen for ErbB-1 and/or ErbB-2 positive estrogen receptor positive primary breast cancer: evidence from a phase III study. J Clin Oncol 2001, 19:38083816.

10. Ravdin P: Aromatase inhibitors for the endocrine adjuvant treatment of breast cancer [editorial]. Lancet 2002, 359:21262127.

11. Jordan VC: Designer estrogens. Sci Am 1998, 279:60-67.

12. Jordan VC: Selective estrogen receptor modulation: a personal perspective. Perspectives in Cancer Research. Cancer Res 2001, 61:5683-5687.

13. Cummings SR, Eckert S, Krueger KA, Grady D, Powles TJ, Cauley JA, Norton L, Nickelsen T, Bjarnason NH, Morrow M, Lippman ME, Black D, Glusman JE, Costa A, Jordan VC: The effect of raloxifene on risk of breast cancer in postmenopausal women: 
results from the MORE randomized trial. Multiple Outcomes of Raloxifene Evaluation. JAMA 1999, 281:2189-2197.

14. Hershman D, Sundararajan V, Jacobson JS, Heitjan DF, Neugut Al, Grann VR. Outcomes of tamoxifen for breast cancer in very high risk women: a cost effectivness analysis. J Clin Oncol 2002, 20:9-16.

15. Jordan VC, Morrow MM: Chemoprevention of breast cancer: a model for change. J Clin Oncol 2002, 20:1-2.

16. Jordan VC, Morrow M: Raloxifene as a multifunctional medicine? BMJ 1999, 319:331-332.

17. Lerner LJ, Jordan VC: The development of antiestrogens for the treatment of breast cancer. Cancer Res 1990, 50:41774189.

18. Jordan VC, Gapstur S, Morrow M: Selective estrogen receptor modulation to reduce breast cancer risk, osteoporosis and coronary heart disease. J Natl Cancer Inst 2001, 93:14491457.

19. Jordan VC: Antiestrogens and selective estrogen receptor modulators as multifunctional medicines. J Med Chem 2002, in press. 